Article DOI: https://doi.org/10.35219/im.2018.1.03

\title{
COMPUTER-ASSISTED ANALYSIS CAD, CAE, CAM OF THE BEARING BODY PART
}

\author{
Assoc. Dr. Eng. Dorin EFTIMIE \\ MECMET - The Research Center of Machines, \\ Mechanic and Technological Equipment \\ Engineering and Agronomy Faculty of Braila \\ "Dunarea de Jos" University of Galati
}

\begin{abstract}
The paper presents a computer-assisted analysis CAD, CAE, CAM of the bearing body in order to optimize the design of the execution technology, eliminating the costs related to the production launch.
\end{abstract}

KEYWORDS: bearing body, CAD, CAM, CAE.

\section{THE 3D MODELING OF THE BEARING BODY PART (CAD)}

The 3D modeling of the bearing body part was made using the specialized software NX 8.0 from Siemens. [1]

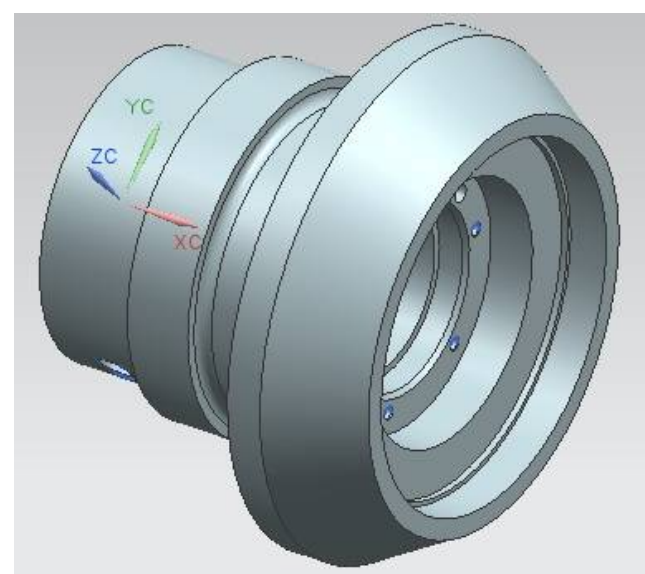

Fig. 1 - The 3D model of the bearing body part

\section{CAE ANALYSIS OF THE BEARING BODY PART}

At this stage (shown in figures from 2 to 7 ), the model is a continuum, with infinite points, as a required structure. Meshing is the fundamental approach required by the $\mathrm{CAE}$ analysis and consists in the transition from the continuous structure (with infinity of points) to a hushed model, with a finite number of points (nodes). This operation is done by "covering" the model with a meshing network and is justified by the fact that, from a practical, engineering point of view, the structure information (such as knowing the values of movements and tensions) is sufficient, in a finite number of points of the model, their number being as large as possible.

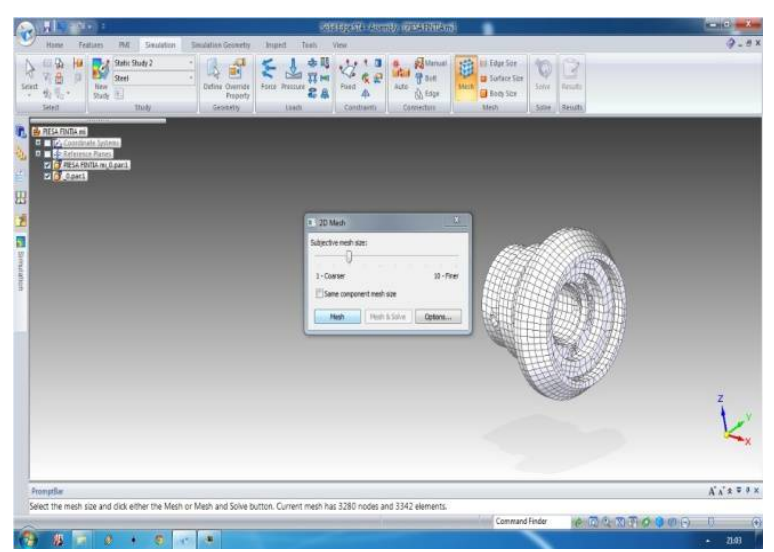

Fig. 2 - Meshing of the finite element

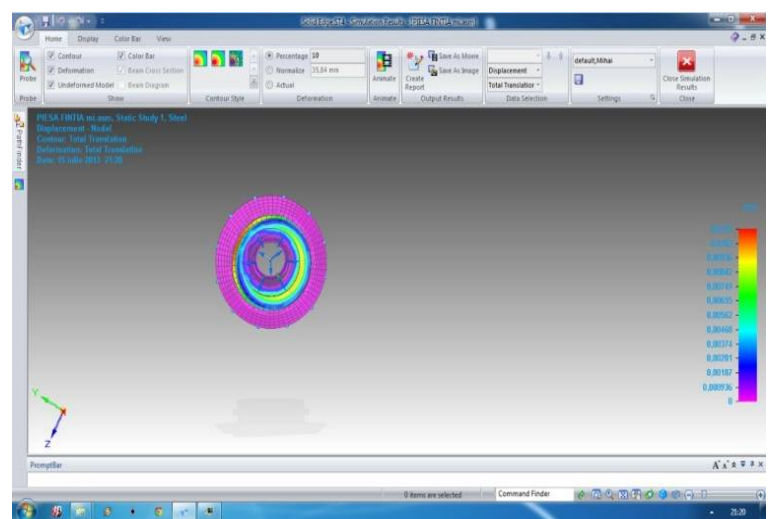

Fig. 3 - Modal analysis, own frequencies 


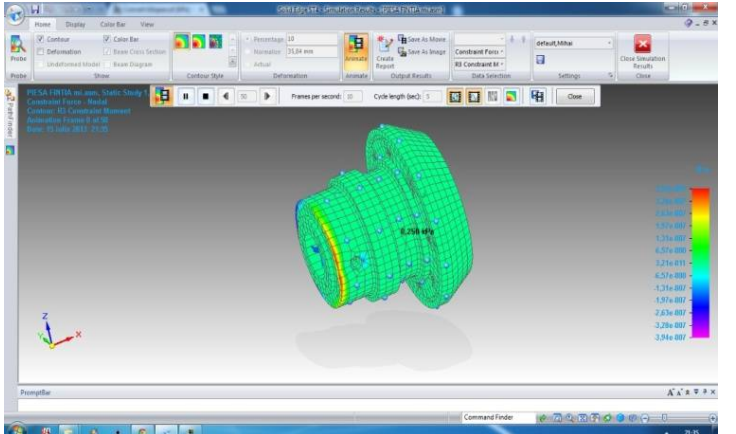

Fig. 4 - Static analysis of the loads on the bearing body

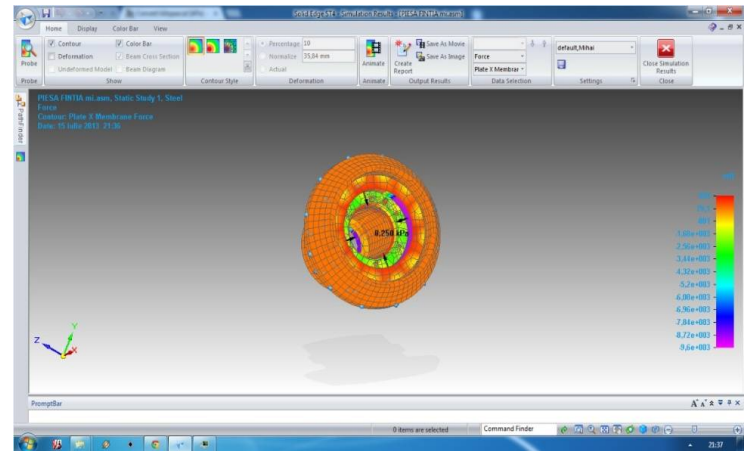

Fig. 5 - Static analysis of the loads on the bearing body

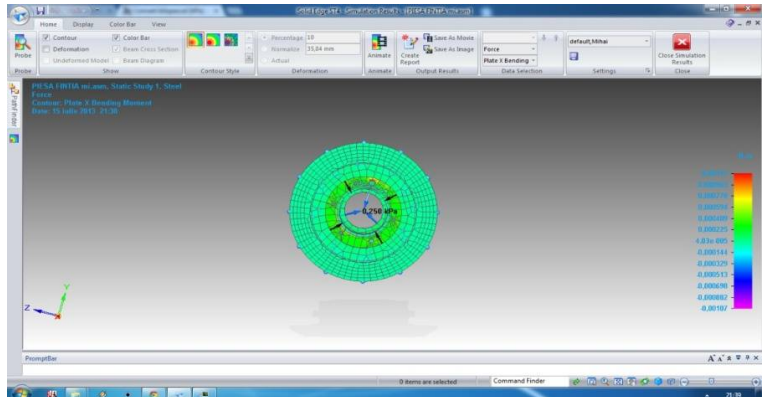

Fig. 6 - Static analysis of the loads on the bearing body

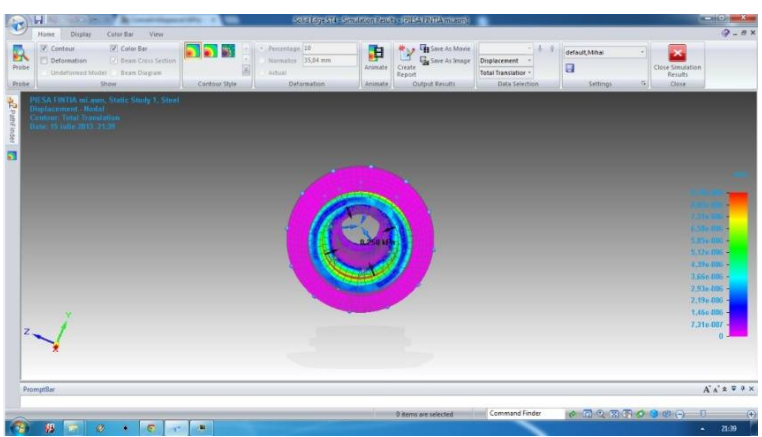

Fig. 7 - Static analysis of the loads on the bearing body

\section{CAM ANALYSIS OF THE BEARING BODY PART}

The figures from 8 to 15 show the technological process of manufacture of the bearing body part. [2]

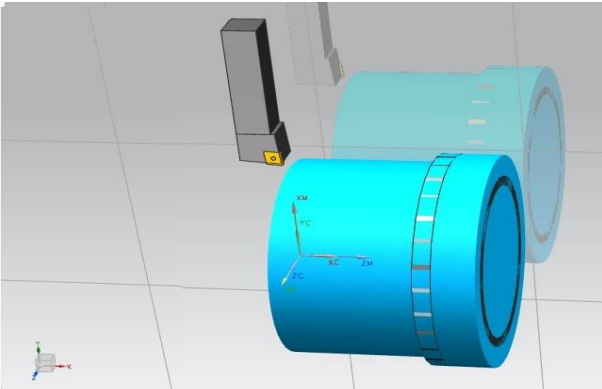

Fig. 8 - Exterior turning

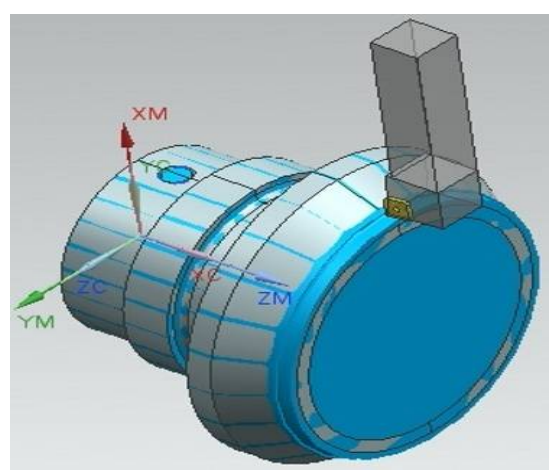

Fig. 9 - Exterior turning

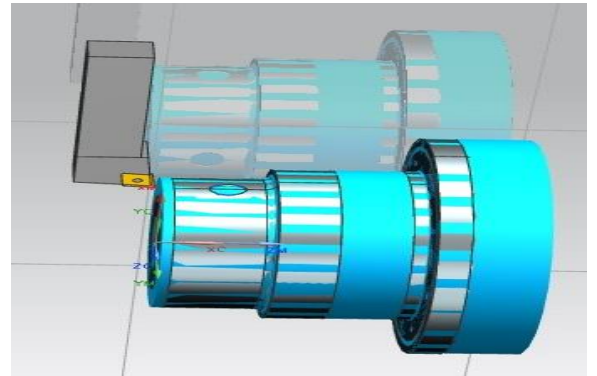

Fig. 10 - Exterior cylindrical turning

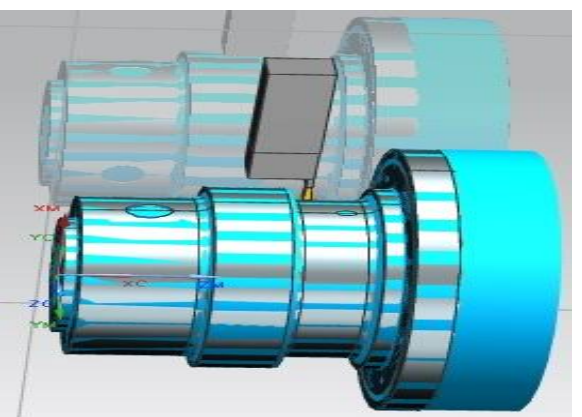

Fig. 11 - Exterior cylindrical turning

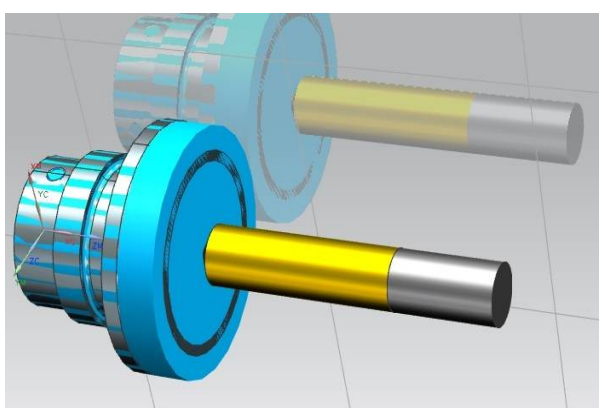

Fig. 12 - Drilling 


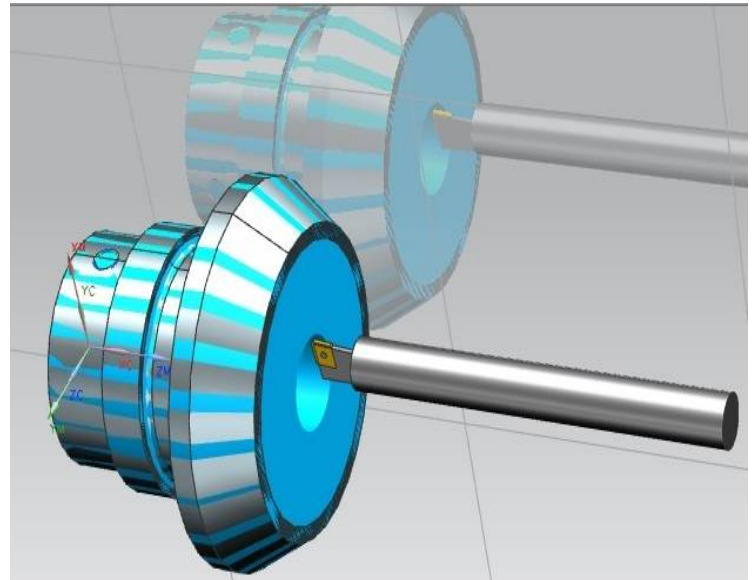

Fig. 13 - Interior cylindrical turning

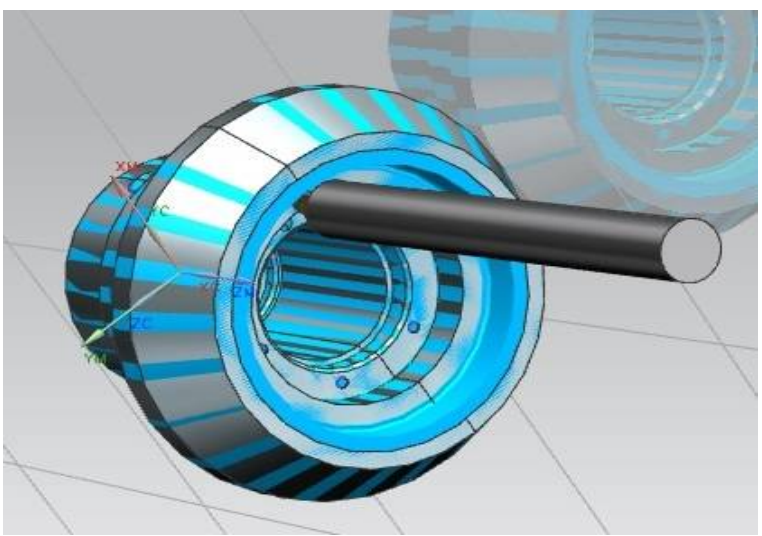

Fig. 14 - Interior turning

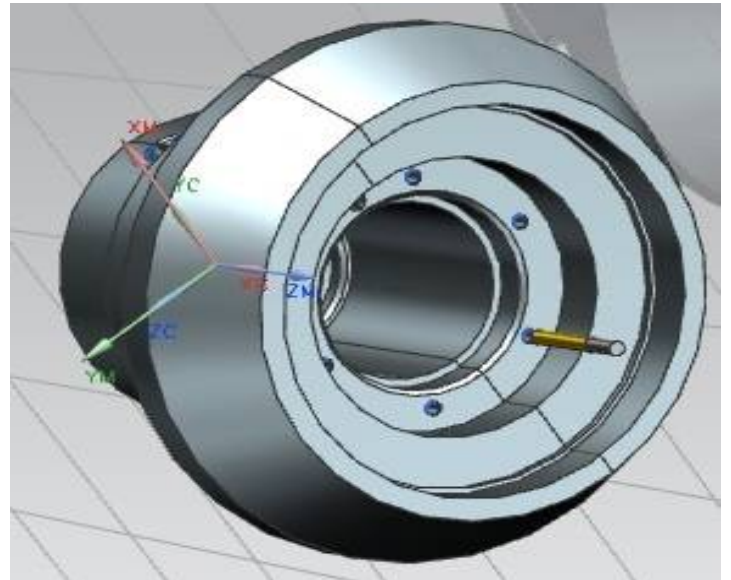

Fig. 15 - Drilling and threading

The quality and precision requirements of the processing are very strict, the only equipment capable of such performances being the CNC machining centers Mazak Integrex e410 H II Etower.

Figure 16 shows the entire manufacturing technology of the bearing body part as well as the times related to the norming for each operation and the phase according to the processing regimes imposed by the software. Thus, a rigorous analysis of the processing technology and the knowledge of the costs in order to optimize the productivity can be allowed.

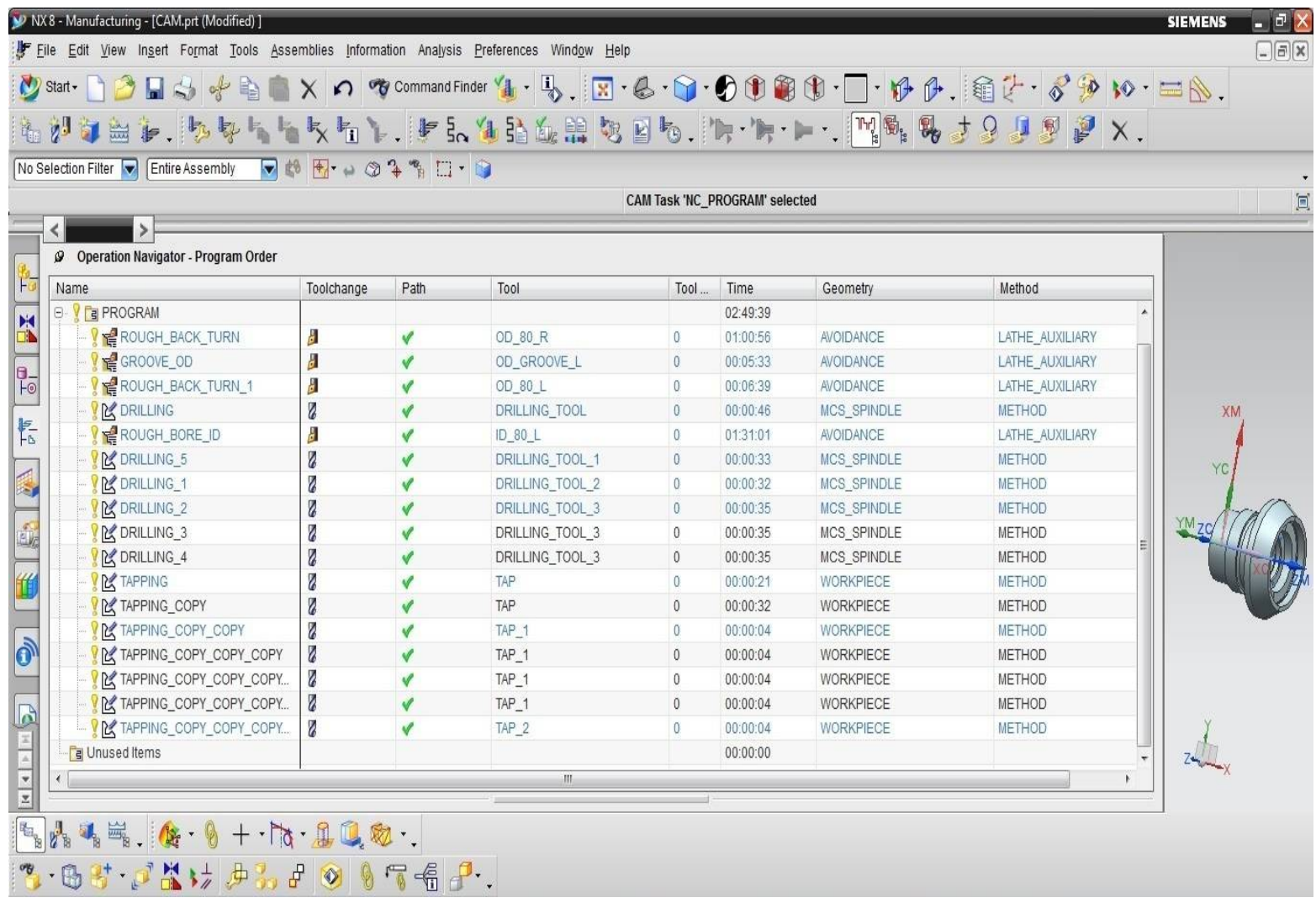

Fig. 16 - Norming data resulting from CAM design 


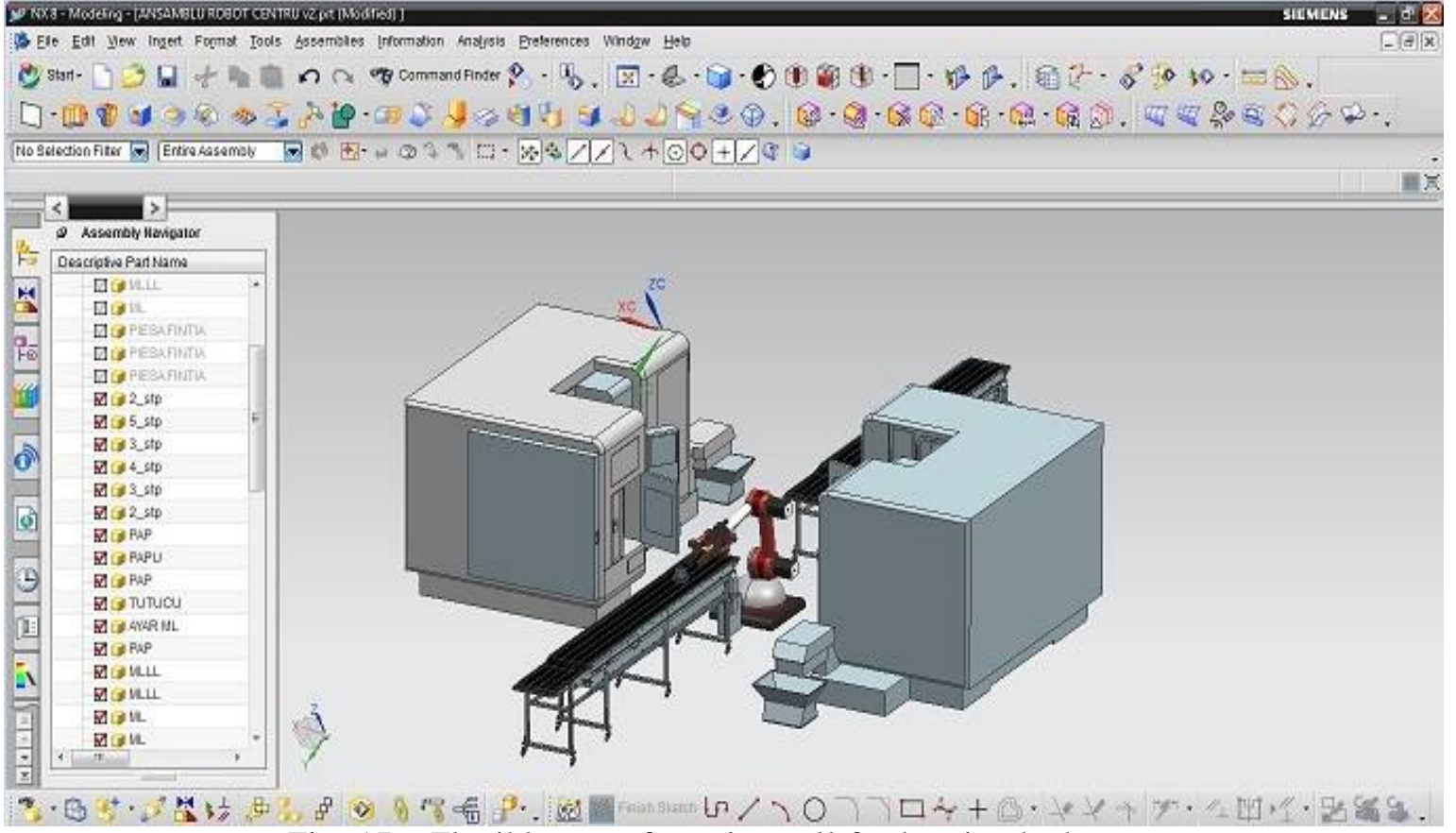

Fig. 17 - Flexible manufacturing cell for bearing body part

\section{FLEXIBLE CELL MODELING}

In order to obtain a clearer image of the flexible manufacturing cell (fig. 17) to be implemented to reduce the production costs for the bearing body part, it was realized with the help of the CAD environment of NX 8.0 software, three-dimensional modeling of the machining centers, of the rolling belts and of the manipulator robot, following their assembly into a flexible manufacturing cell.

\section{CONCLUSIONS}

Flexibility is a necessity of the production systems and consists in the automation of the technological processes that have a rapid adaptation capacity in the modification of the manufacturing technology.

The flexible machining system for this type of part is an optimized solution and can be defined as an integrated set of machine tools served by an automatic system of transport, handling and storage of the semi-finished products, finished parts and tools, provided with automated equipment for measurement and testing, capable of performing, under the command of the computer, the simultaneous or successive processing of different parts, belonging to a certain family of products, under the conditions of minimal intervention of the human operator and with minimum adjustment times.

\section{REFERENCES}

[1] High-End solution CAD/CAM/CAE Siemens NX 8.0.

[2] Assoc. dr. eng. Dorin Eftimie: Digital product manufacturing using the virtual prototype. Course notes. 